\title{
Antibacterial Defense of Human Airway Epithelial Cells from Chronic Obstructive Pulmonary Disease Patients Induced by Acute Exposure to Nontypeable Haemophilus influenzae: Modulation by Cigarette Smoke
}

\author{
Gimano D. Amatngalim ${ }^{a}$ Jasmijn A. Schrumpf ${ }^{a}$ Almira Henic $^{a}$ \\ Esther Dronkers $^{a}$ Renate M. Verhoosel ${ }^{a}$ Soledad R. Ordonez ${ }^{c}$ \\ Henk P. Haagsman ${ }^{c}$ Maria E. Fuentes ${ }^{d}$ Sriram Sridhard Jamil Aarbiou ${ }^{b}$ \\ Richard A.J. Janssen ${ }^{b}$ Annemarie N. Lekkerkerker ${ }^{b}$ Pieter S. Hiemstra ${ }^{a}$ \\ ${ }^{a}$ Department of Pulmonology, Leiden University Medical Center, and ${ }^{\mathrm{b}}$ Galapagos BV, Leiden, and ${ }^{\mathrm{c}}$ Department of \\ Infectious Diseases and Immunology, Division Molecular Host Defence, Faculty of Veterinary Medicine, Utrecht \\ University, Utrecht, The Netherlands; ${ }^{\mathrm{d}}$ Hoffmann La Roche, Nutley, NJ, USA
}

\section{Keywords}

Antimicrobial peptides · Epithelium · Host defense · Chronic obstructive pulmonary disease $\cdot$ Cigarette smoke

\begin{abstract}
Antimicrobial proteins and peptides (AMPs) are a central component of the antibacterial activity of airway epithelial cells. It has been proposed that a decrease in antibacterial lung defense contributes to an increased susceptibility to microbial infection in smokers and patients with chronic obstructive pulmonary disease (COPD). However, whether reduced AMP expression in the epithelium contributes to this lower defense is largely unknown. We investigated the bacterial killing activity and expression of AMPs by air-liquid interface-cultured primary bronchial epithelial cells from COPD
\end{abstract}

patients and non-COPD (ex-)smokers that were stimulated with nontypeable Haemophilus influenzae (NTHi). In addition, the effect of cigarette smoke on AMP expression and the activation of signaling pathways was determined. COPD cell cultures displayed reduced antibacterial activity, whereas smoke exposure suppressed the NTHi-induced expression of AMPs and further increased IL-8 expression in COPD and nonCOPD cultures. Moreover, smoke exposure impaired NTHiinduced activation of NF-KB, but not MAP-kinase signaling. Our findings demonstrate that the antibacterial activity of cultured airway epithelial cells induced by acute bacterial exposure was reduced in COPD and suppressed by cigarette smoke, whereas inflammatory responses persisted. These findings help to explain the imbalance between protective antibacterial and destructive inflammatory innate immune responses in COPD.

(c) 2017 The Author(s)

Published by S. Karger AG, Basel

\begin{tabular}{ll}
\hline KARGER & $\begin{array}{l}\text { ( } 2017 \text { The Author(s) } \\
\text { Published by S. Karger AG, Basel Oparger }\end{array}$ \\
E-Mail karger@karger.com & \\
www.karger.com/jin & This article is licensed under the Creative Commons Attribution- \\
& $\begin{array}{l}\text { NonCommercial-NoDerivatives 4.0 International License (CC BY- } \\
\text { NC-ND) (http://www.karger.com/Services/OpenAccessLicense). } \\
\text { Usage and distribution for commercial purposes as well as any dis- } \\
\text { tribution of modified material requires written permission. }\end{array}$
\end{tabular}

Dr. Gimano D. Amatngalim

Department of Pulmonology, Leiden University Medical Center Albinusdreef 2

NL-2333 ZA Leiden (The Netherlands)

E-Mail g.d.amatngalim@lumc.nl 


\section{Introduction}

Chronic obstructive pulmonary disease (COPD) is a severe inflammatory lung disorder in which colonization and infections with opportunistic respiratory bacteria are a major disease hallmark [1]. It is hypothesized that a vicious circle of attenuated antibacterial lung defense, enhanced bacterial colonization, and the induction of lung inflammation and injury contribute to the disease [2]. However, the underlying mechanisms remain incompletely understood.

Smoking is the main risk factor for COPD development, and is furthermore associated with an increased susceptibility to respiratory infections [3]. Despite the strong association, only a subpopulation of approximately $15-20 \%$ of smokers develop the disease. This suggests that there are differences between susceptible smokers and smokers with a normal lung function that may help to explain disease etiology. These differences may persist in cell culture $[4,5]$; for this reason, comparison of cell cultures from COPD patients and non-COPD smokers may reveal differences in host defense activities that may help to explain the increased microbial susceptibility.

Airway epithelial cells contribute to innate lung defense by displaying direct antibacterial activity, which is mediated in part by the production of antimicrobial proteins and peptides (AMPs) $[6,7]$. In addition to AMPs that are expressed on a steady-state basis, others are induced for example upon the recognition of microbes or microbial structures by pattern recognition receptors. This response is highly similar amongst species, and murine models have shown that the inducible antibacterial activity of airway epithelial cells provides full protection against various pathogenic microbes without further involvement of immune cells [8]. Impairment of this induced activity in COPD might therefore contribute to the increased susceptibility to infection with respiratory pathogens.

Observational studies in lung tissue, airway secretions, and tracheal washings have shown that the expression of several AMPs is reduced in smokers and patients with COPD, including the microbial-induced antimicrobial peptide human $\beta$-defensin-2 (hBD-2) [9-12]. Moreover, it has been demonstrated that cigarette smoke (CS) exposure attenuated the antibacterial activity and microbialinduced expression of hBD-2 in cultured airway epithelial cells [12-14]. This suggests that the inducible antibacterial activity is affected in airway epithelial cells from smokers and COPD patients. However, it is unclear whether this activity differs between airway epithelial cells from non-COPD smokers and COPD patients. Interestingly, microbial-induced expression of the proinflammatory mediator IL-8 is not reduced by CS $[14,15]$. Conflicting to this, cellular signal transduction pathways regulating the expression of AMPs and proinflammatory mediators largely overlap $[16,17]$, and it is unknown whether imbalances in these signaling pathways reflect the alterations in AMP and proinflammatory mediator expression.

To gain greater insight into the role of the inducible antibacterial defense function of airway epithelial cells in COPD, we examined the antibacterial activity and expression of AMPs following acute bacterial exposure of cultured airway epithelial cells from mild-to-moderate COPD patients and (ex-)smokers with a normal lung function (non-COPD). To understand the mechanism underling reduced AMP expression, we determined the effect of CS on the microbial-induced expression of AMPs, and the regulation of cellular signal transduction pathways.

\section{Materials and Methods}

Primary Bronchial Epithelial Cell Cultures and Stimuli

Primary bronchial epithelial cells (PBEC) were isolated from tumor-free resected lung tissue and cultured in an air-liquid interface model (further referred to as ALI-PBEC) to obtain mucociliary-differentiated cultures, essentially as previously described $[14,18]$. PBEC cultures were used from a total of 28 patients, all undergoing lung resection surgery for lung cancer. Clinical histories and lung function data were obtained from anonymized patients. Disease status was determined based on lung function according to the Global Initiative for Chronic Obstructive Lung Disease classification [19]. The patients included 15 COPD and 13 non-COPD subjects (see Tables 1 and 2 for indicated experiments). Both groups included current smokers and ex-smokers. Nontypeable Haemophilus influenzae (NTHi) strain D1 [20] was cultured and ultraviolet (UV) inactivated as described earlier [14]. UV-inactivated NTHi was applied to the apical surface of ALI-PBEC in a volume of $100 \mu \mathrm{L}$; PBS was used for dilutions and as a negative control. ALI-PBEC were exposed to mainstream CS from 3R4F reference cigarettes (University of Kentucky, Lexington, KY, USA) using a previously described exposure model $[14,15]$. In brief, epithelial cultures were placed in room air (AIR; control) or CS exposure chambers, localized in a tissue incubator at $37^{\circ} \mathrm{C}$ and $5 \% \mathrm{CO}_{2}$. In these exposure chambers, ALI-PBEC were respectively exposed to AIR or CS from 1 cigarette (approximately $2 \mathrm{mg}$ of CS particles), which was infused by a mechanical pump with a continuous flow of $1 \mathrm{~L} / \mathrm{min}$ for a period of 4-5 min. Residual CS was removed by flushing the chamber with air derived from the incubator for $10 \mathrm{~min}$. After exposure, cells were stimulated at the apical surface with UV-inactivated NTHi or PBS (negative control).

\section{Bacterial Killing Assay}

The bacterial killing assay was adapted from Pezzulo et al. [21]. Instead of golden grids, bacteria were linked to glass coverslips. Six-millimeter-round coverslips were rinsed in ethanol, dried at room temperature, and subsequently silanized with $2 \%(\mathrm{v} / \mathrm{v})$
360

J Innate Immun 2017;9:359-374

DOI: $10.1159 / 000455193$
Amatngalim et al. 
Table 1. Patient characteristics for use of the bacterial killing assay

\begin{tabular}{lllc}
\hline & COPD & Non-COPD & $p$ value \\
\hline$n$ & 5 & 5 & \\
Female/male & $2 / 3$ & $2 / 3$ & \\
Age, years & $66 \pm 11$ & $64 \pm 7$ & 0.6 \\
FEV $_{1}, \%$ predicted & $68 \pm 17$ & $96 \pm 14$ & 0.05 \\
FEV $_{1}$ /FVC, \% & $58 \pm 7$ & $78 \pm 4$ & $<0.01$ \\
\hline
\end{tabular}

Age and lung function data are shown as means \pm SD. The mean differences in $\mathrm{FEV}_{1}$ and $\mathrm{FEV}_{1} / \mathrm{FVC}$ were compared using the nonparametric Mann-Whitney test. COPD, chronic obstructive pulmonary disease; $\mathrm{FEV}_{1}$, forced expiratory volume in $1 \mathrm{~s}$; FVC, forced vital capacity.

Table 2. Patient characteristics for NTHi-induced AMP expression

\begin{tabular}{lclc}
\hline & COPD & Non-COPD & $p$ value \\
\hline$n$ & 12 & 8 & \\
Female/male & $3 / 9$ & $2 / 6$ & \\
Age, years & $68 \pm 8$ & $66 \pm 8$ & 0.56 \\
FEV $_{1}, \%$ predicted & $64 \pm 21$ & $85 \pm 15$ & 0.04 \\
FEV $_{1}$ /FVC, \% & $55 \pm 10$ & $80 \pm 9$ & $<0.0001$ \\
\hline
\end{tabular}

Age and lung function are shown as means \pm SEM. The mean differences in $\mathrm{FEV}_{1}$ and $\mathrm{FEV}_{1} / \mathrm{FVC}$ were compared using the nonparametric Mann-Whitney test. COPD, chronic obstructive pulmonary disease; $\mathrm{FEV}_{1}$, forced expiratory volume in $1 \mathrm{~s}$; FVC, forced vital capacity.

APTES ([3-aminopropyl] triethoxysilane, $\mathrm{H}_{2} \mathrm{~N}\left(\mathrm{CH}_{2}\right)_{3} \mathrm{Si}\left(\mathrm{OC}_{2} \mathrm{H}_{5}\right)_{3}$; Sigma-Aldrich) solution in acetone for $10 \mathrm{~s}$. After rinsing in $\mathrm{H}_{2} \mathrm{O}$ for $10 \mathrm{~min}$ and drying at room temperature, the coverslips were immersed in $1 \mathrm{mM}$ of MUA (11-mercaptoundecanoic acid, $\mathrm{HS}\left(\mathrm{CH}_{2}\right)_{10} \mathrm{COOH}$, Sigma-Aldrich) for $30 \mathrm{~min}$ at room temperature. Afterwards, coverslips were incubated in $0.1 \mathrm{M}$ of NHS $(\mathrm{N}$ hydroxysuccinimide) and $0.1 \mathrm{M}$ of EDC (1-ethyl-3-[3-dimethylaminopropyl]carbodiimide, 1:2 molar ratio; both from Sigma-Aldrich) for $30 \mathrm{~min}$, and subsequently coated for $30 \mathrm{~min}$ with $10 \mu \mathrm{g} /$ $\mathrm{mL}$ of streptavidin (Sigma-Aldrich) in PBS. Next, the coverslips were washed and immersed with $1 \mathrm{M}$ of glycine for $30 \mathrm{~min} .1 \times 10^{8}$ $\mathrm{CFU} / \mathrm{mL}\left(\mathrm{OD}_{600}\right)$ of log phase growth cultured NTHi was incubated in $0.88 \mathrm{mg} / \mathrm{mL}$ of $\mathrm{N}$-hydroxysulfosuccinimide-biotin (sulfoNHS-biotin; Thermo Scientific) for $30 \mathrm{~min}$ on ice. Next, biotinlabeled NTHi was linked to the surface of the streptavidin-coated glass coverslips in PBS for $30 \mathrm{~min}$ and subsequently washed twice in PBS and finally in $0.01 \mathrm{M}$ of phosphate buffer $\mathrm{pH} 7.4$, to remove the unbound bacteria. The bacterial killing activity was determined of ALI-PBEC that were prestimulated with UV-inactivated NTHi or PBS (untreated control), which was applied at the apical surface. After $6 \mathrm{~h}$ of incubation, cultures were washed with PBS and incubated for $48 \mathrm{~h}$. Afterwards, NTHi-coated coverslips were placed on the apical surface of ALI-PBEC for $1 \mathrm{~min}$. The coverslips were subsequently stained for $30 \mathrm{~s}$ with SYTO 9 and propidium iodide (both Life Technologies, Darmstadt, Germany), to visualize the live and dead bacteria, respectively. The coverslips were mounted on microscopic slides and covered in Baclight mounting oil (Life Technologies). Digital images were made with a Zeiss Axio Scope A1 fluorescent microscope and Zeiss Axiocam mRc 5 camera (Carl Zeiss Microscopy, Göttingen, Germany). The number of live and dead bacteria was analyzed using Image J software (National Institutes of Health, Bethesda, MD, USA). The bacterial killing activity was determined by calculating the percentage of dead bacteria.

\section{Microarray Gene Expression Analysis}

Primary bronchial epithelial cells from 6 different donors were cultured in submerged conditions as previously described [14]. Cells were left unstimulated or triggered with UV-killed NTHi. RNA from these cultures were then isolated at 2 timepoints, early $(6 \mathrm{~h})$ and late $(24 \mathrm{~h})$, and subsequently subject to whole genome profiling of gene expression by microarray (Affymetrix GeneTitan platform).

\section{Quantitative Real-Time PCR}

RNA was isolated from ALI-PBEC using the miRNeasy Mini Kit (Qiagen, Venlo, The Netherlands) according to the manufacturer's protocol. RNA quantities were determined using the Nanodrop ND-1000 UV-visible (UV-Vis) spectrophotometer (Nanodrop Technologies, Wilmington, DE, USA) and cDNA was synthesized by reverse transcription PCR of $1 \mu \mathrm{g}$ of RNA, using oligo-dT primers (Qiagen) and Moloney murine leukemia virus polymerase (Promega, Leiden, The Netherlands). Quantitative real-time PCR (qPCR) was conducted using IQ SYBR green supermix (Bio-Rad) and a CFX-384 real-time PCR detection system (Bio-Rad). qPCR reactions were performed using the primers shown in Table 3. The housekeeping genes RPL13A and ATP5B were selected using the "Genorm method" (Genorm; Primer Design, Southampton, UK). Bio-Rad CFX manager 3.0 software (BioRad) was used to calculate the arbitrary gene expression using the standard curve method.

\section{ELISA}

Secretion of innate immune mediators by ALI-PBEC was determined in the apical surface liquid, collected by washing the apical surface with $100 \mu \mathrm{L}$ of PBS for $15 \mathrm{~min}$, and in the basal medium as indicated. The secretion of IL-8 (Sanquin, Amsterdam, The Netherlands) and CCL20 (R\&D, Minneapolis, MN, USA) was determined by ELISA following the manufacturer's protocol. Reagent for hBD-2 detection was a generous gift from $\mathrm{D}$. Proud (Calgary, $\mathrm{AB}, \mathrm{Canada}$ ), and the hBD-2 ELISA was conducted as previously described [22]. The optical density values were measured with a microplate reader (Bio-Rad).

\section{Transepithelial Electrical Resistance}

The epithelial barrier integrity of ALI-PBEC cultures was determined by measuring the transepithelial electrical resistance (TEER) using the MilliCell-ERS (Millipore, Bedford, MA, USA).

\section{Western Blot}

ALI-PBEC were washed 3 times with cold PBS and cell lysis was performed in lysis buffer consisting of $150 \mathrm{mM}$ of $\mathrm{NaCl}, 50 \mathrm{mM}$ of Tris $\mathrm{HCl} \mathrm{pH} \mathrm{7.4,} \mathrm{0.1 \%} \mathrm{NP-40} \mathrm{(v/v),} \mathrm{and} \mathrm{EDTA-free} \mathrm{protease} \mathrm{in-}$ 
Table 3. qPCR primer sequences

\begin{tabular}{|c|c|c|}
\hline Gene & Forward primer $\left(5^{\prime}-3^{\prime}\right)$ & Reverse primer $\left(5^{\prime}-3^{\prime}\right)$ \\
\hline DEFB4/hBD-2 & ATCAGCCATGAGGGTCTTG & GCAGCATTTTGTTCCAGG \\
\hline CCL20 & GCAAGCAACTTTGACTGCTG & TGGGCTATGTCCAATTCCAT \\
\hline LCN2 & CCTCAGACCTGATCCCAGC & CAGGACGGAGGTGACATTGTA \\
\hline S100A7 & ACGTGATGACAAGATTGACAAGC & GCGAGGTAATTTGTGCCCTTT \\
\hline TLR2 & TCTCGCAGTTCCAAACATTCCAC & TTTATCGTCTTCCTGCTTCAAGCC \\
\hline ATF3 & CCTCTGCGCTGGAATCAGTC & TTCTTTCTCGTCGCCTCTTTTT \\
\hline pri-mir-147b & TTCATGACTGTGGCGGCGGG & GGCGAGGGCTCGTCATTTGGT \\
\hline A20 & TCCTCAGGCTTTGTATTTGAGC & TGTGTATCGGTGCATGGTTTTA \\
\hline DEFB3/hBD-3 & AGCCTAGCAGCTATGAGGATC & CTTCGGCAGCATTTTGCGCCA \\
\hline CAMP/LL-37 & TCATTGCCCAGGTCCTCAG & TCCCCATACACCGCTTCAC \\
\hline SLPI & GAGATGTTGTCCTGACACTTGTG & AGGCTTCCTCCTTGTTGGGT \\
\hline DEFB1/hBD-1 & ATGAGAACTTCCTACCTTCTGCT & TCTGTAACAGGTGCCTTGAATTT \\
\hline IL8 & CAGCCTTCCTGATTTCTG & САСТTСТССАСААСССТСТGC \\
\hline IL6 & CAGAGCTGTGCAGATGAGTACA & GATGAGTTGTCATGTCCTGCAG \\
\hline NFKBIA & TGTGCTTCGAGTGACTGACC & TCACCCCACATCACTGAACG \\
\hline ZC3H12A & GTACGTCTCCCAGGATTGCC & GGGACTGTAGCCCGTGTAAG \\
\hline NFKBIZ & AGAGGCCCCTTTCAAGGTGT & TCCATCAGACAACGAATCGGG \\
\hline FOS & CCTAACCGCCACGATGATGT & TCTGCGGGTGAGTGGTAGTA \\
\hline JUN & TCCTGCCCAGTGTTGTTTGT & GACTTCTCAGTGGGCTGTCC \\
\hline FOSL1 & AACCGGAGGAAGGAACTGAC & CTGCAGCCCAGATTTCTCAT \\
\hline RPL13A & AAGGTGGTGGTCGTACGCTGTG & CGGGAAGGGTTGGTGTTCATCC \\
\hline$A T P 5 B$ & TCACCCAGGCTGGTTCAGA & AGTGGCCAGGGTAGGCTGAT \\
\hline
\end{tabular}

hibitor cocktail (Roche, Basel, Switzerland). Samples were subsequently mixed with sample buffer, consisting of $0.5 \mathrm{M}$ of Tris $\mathrm{pH}$ $6.8,10 \%$ SDS (w/v), 20\% glycerol (v/v), $0.02 \%$ bromophenol blue, and $50 \mathrm{mM}$ of DTT. Nuclear fractions were isolated using the NEPER Nuclear Protein Extraction Kit (Thermo Scientific, Rockford, IL, USA) according to the manufacturer's protocol. Protein samples were separated by SDS-PAGE gel electrophoresis on $10 \%$ glycine-based gels and transferred to polyvinylidene difluoride membranes. Membranes were blocked in 5\% (w/v) skimmed milk (Sigma-Aldrich) in PBS/0.05\% (v/v) Tween-20 and stained with primary antibodies in 5\% (w/v) BSA PBS/0.05\% (v/v) Tween-20 overnight at $4{ }^{\circ} \mathrm{C}$. Antibodies were used to detect $\mathrm{p}$-IKKa $/ \beta, \mathrm{IKK} \beta$, I $\mathrm{B}-\alpha, \mathrm{p}$ - and t-ERK1/2, p- and t-p38, TBP (all Cell Signaling, Beverly, MA, USA), p50, p65 (both Santa Cruz Biotechnology, Santa Cruz, CA, USA), and $\beta$-actin (Leica). Next, membranes were stained with secondary HRP-labeled antibody (Sigma-Aldrich) in $5 \%(\mathrm{w} / \mathrm{v})$ skimmed milk (Sigma-Aldrich) in PBS/0.05\% (v/v) Tween-20 for $1 \mathrm{~h}$. Afterwards, membranes were developed with enhanced chemiluminescence substrate (Thermo Scientific). The intensity of bands were quantified by densitometry using Image J software (National Institutes of Health, Bethesda, MD, USA).

\section{Immunofluorescence Confocal Microscopy}

ALI-PBEC were fixed in $4 \%$ paraformaldehyde for $30 \mathrm{~min}$, permeabilized in $100 \%$ methanol for $10 \mathrm{~min}$ at $4{ }^{\circ} \mathrm{C}$, and blocked in blocking solution consisting of $5 \%(\mathrm{w} / \mathrm{v})$ BSA, $0.3 \%(\mathrm{v} / \mathrm{v})$ Triton X in PBS. Between each step, cells were washed 3 times with PBS. Afterwards, the PBEC-containing filters were cut from the Transwell using a razorblade and subsequently incubated overnight at $4{ }^{\circ} \mathrm{C}$ with anti-mouse $\mathrm{p} 50$ or anti-rabbit p65 primary anti- bodies (both Santa Cruz Biotechnology) diluted in blocking solution. Next, filters were washed 3 times in PBS and stained with goat anti-rabbit AlexaFluor 568 or goat anti-mouse AlexaFluor 488 (both Life Technologies), respectively, and DAPI as nuclear staining. Secondary antibodies and DAPI were diluted in blocking solution and incubated in the dark for $30 \mathrm{~min}$ at room temperature. Afterwards, the filters were washed 3 times with PBS and mounted on coverslips with Vectashield Hard Set Mounting Medium (Vector Lab, Burlingame, CA, USA). Images were made using a Leica TCS SP5 confocal inverted microscope (Leica Microsystems) and processed using the Leica Application Suite Advanced Fluorescence software (LAS AF; Leica Microsystems).

Data Analysis

Statistical analysis was performed in GraphPad PRISM 6.0 (GraphPad Software Inc., La Jolla, CA, USA). The analysis of differences was conducted with a 1- or 2-way repeated measurements ANOVA and Bonferroni post hoc test and (un)paired Student $t$ test as indicated. Differences were considered significant with $p<0.05$.

\section{Results}

Lower NTHi-Induced Antibacterial Activity by COPD Airway Epithelial Cells

We first determined the bacterial killing activity of cultured ALI-PBEC from COPD patients and non-COPD (ex-)smokers. ALI-PBEC were first stimulated at the api-
362

J Innate Immun 2017;9:359-374

DOI: $10.1159 / 000455193$
Amatngalim et al. 


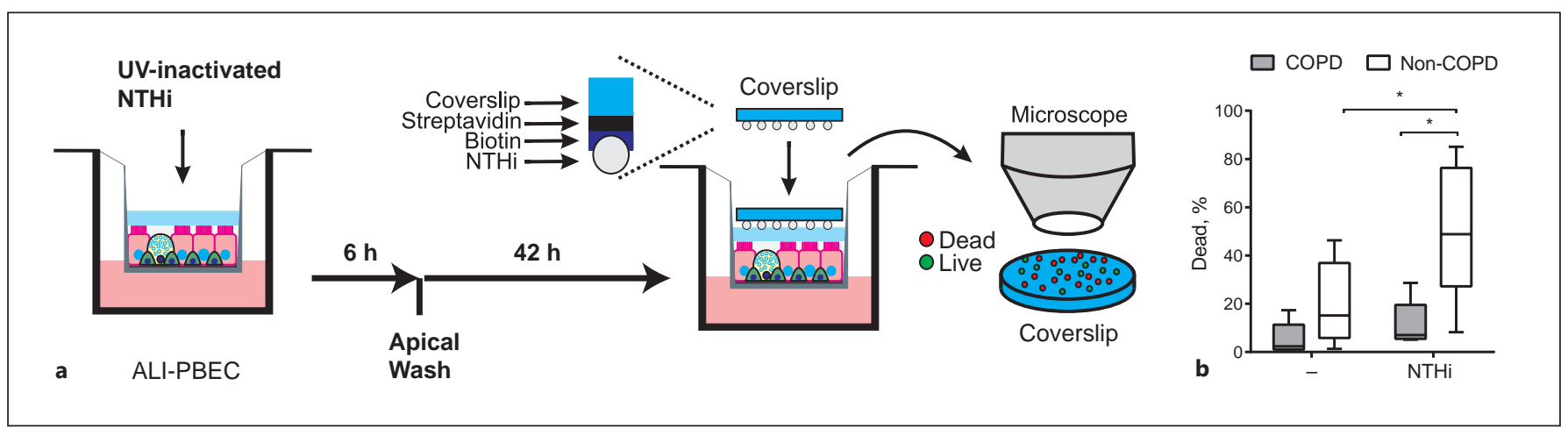

Fig. 1. Impaired bacterial killing by COPD ALI-PBEC. a Schematic representation of the bacterial killing assay. ALI-PBEC cultures were stimulated with $0.5 \times 10^{9} \mathrm{CFU} / \mathrm{mL} \mathrm{UV}$-inactivated NTHi or PBS as the negative control for $6 \mathrm{~h}$, washed at the apical surface, and incubated for $42 \mathrm{~h}$. Next, streptavidin-coated glass coverslips linked to biotin-bound NTHi were placed on the apical surface of ALI-PBEC. Bacterial killing was determined by counting individual live and dead bacteria. b Bacterial killing was assessed for cultured ALI-PBEC from COPD patients (gray boxplots, $n=5$ pa-

cal surface with UV-inactivated NTHi or PBS (negative control) to investigate microbial exposure-induced and baseline antibacterial activity. At $6 \mathrm{~h}$ after stimulation, the apical surface was washed and cells were incubated for an additional $42 \mathrm{~h}$ prior to assessment of the antibacterial activity (Fig. 1a). A killing assay was used that allows direct assessment of the antibacterial activity of the airway surface liquid of cultured ALI-PBEC by placing NTHicoated coverslips on the apical surface. Minimal antibacterial activity was seen in control-treated ALI-PBEC from both COPD and non-COPD donors (Fig. 1b). Exposure to NTHi significantly increased the antibacterial activity of non-COPD cultures. In contrast, this increase was not observed in COPD epithelia. These findings suggest that cultured airway epithelial cells from COPD patients have reduced microbial-induced antibacterial activity compared to cell cultures from non-COPD (ex-)smokers.

\section{NTHi-Induced Expression of $h B D-2$ and S100A7 Is}

Altered in COPD ALI-PBEC

To investigate the role of AMPs in the reduced antibacterial activity of COPD airway epithelial cells, we examined the expression of microbial-induced AMPs in COPD and non-COPD ALI-PBEC exposed to various concentrations of UV-inactivated NTHi for $24 \mathrm{~h}$. For this analysis we first focused on microbial-induced AMPs that were found to be highly expressed in submerged cultured and undifferentiated PBEC upon exposure to UV-inacti-

Airway Epithelial Antibacterial Defense in COPD tients) and non-COPD smokers (white boxplots, $n=5$ patients), either unstimulated or stimulated with $0.5 \times 10^{9} \mathrm{CFU} / \mathrm{mL} \mathrm{UV}$ inactivated NTHi. Data are shown as the percentage of dead bacteria. The killing assay was performed in triplicates. COPD and non-COPD comparison results are depicted as boxplots with whiskers from minimum to maximum or bars (means \pm SEM). The analysis of differences was conducted with a 2-way ANOVA and Bonferroni post hoc test. ${ }^{*} p<0.05$.

vated NTHi, based on a microarray gene expression analysis (see online suppl. Table S1; for all online suppl. material, see www.karger.com/doi/10.1159/000455193). These genes included DEFB4, encoding hBD-2, the antimicrobial chemokine CCL20, S100A7, lipocalin 2(LCN2), and S100A7 [23-26]. NTHi stimulation induced the expression of all examined genes in both COPD and nonCOPD cultures (Fig. 2a-d). However, COPD ALI-PBEC displayed lower NTHi-mediated expression of DEFB4 and S100A7 compared to non-COPD cultures (Fig. 2a, b), whereas LCN2 and CCL20 did not reveal statistically significant differences (Fig. 2c, d). We also did not observe differences in the expression of other AMPs that were not observed in the microarray gene expression analysis (LL37/CAMP, SLPI, $\beta$-defensin 1 and 3 [hBD- 1 and hBD-3]; see online suppl. Fig. S1). We further analyzed the NTHiinduced protein secretion of hBD-2 and CCL20 in apical washes and basal medium of COPD and non-COPD ALIPBEC $24 \mathrm{~h}$ after stimulation. In contrast to the mRNA expression, we did not detect a difference in hBD-2 peptide release at the apical surface and basal medium between COPD and non-COPD ALI-PBEC (Fig. 2e, f). Moreover, no differences were observed in secretion of CCL20. To explain this discrepancy between hBD-2 mRNA expression and peptide levels, we examined whether the difference in mRNA expression was time dependent. Indeed, in contrast to NTHi-induced mRNA expression at $24 \mathrm{~h}$, we did not detect differences between

J Innate Immun 2017;9:359-374 DOI: $10.1159 / 000455193$ 
Fig. 2. AMP expression by COPD ALIPBEC is lower compared to non-COPD. COPD (gray boxplots, $n=12$ patients) and non-COPD (white boxplots, $n=8$ patients) ALI-PBEC were stimulated with different concentrations of UV-inactivated NTHi for $24 \mathrm{~h}$. mRNA expression of the AMPs DEFB4/hBD-2 (a), S100A7 (b), LCN2 (c), and CCL20 (d) was assessed by qPCR. Stimulations were performed in duplicate. Data are shown as the fold change in mRNA compared to untreated cells. Assessment of hBD-2 (e) and CCL20 (f) protein secretion in the apical surface liquid (ASL) and basal medium (BM) of COPD (gray boxplots, $n=9$ ) and non-COPD (white boxplots, $n=7-8$ ) ALI-PBEC stimulated with $1 \times 10^{9} \mathrm{CFU} / \mathrm{mL}$ UV-inactivated NTHi for $24 \mathrm{~h}$. Stimulations were performed in duplicate. Results are shown as boxplots with whiskers from minimum to maximum or bars (means \pm SEM). The analysis of differences was conducted with a 2-way ANOVA and Bonferroni post hoc test. ${ }^{*} p<0.05,{ }^{* *} p<0.01$.

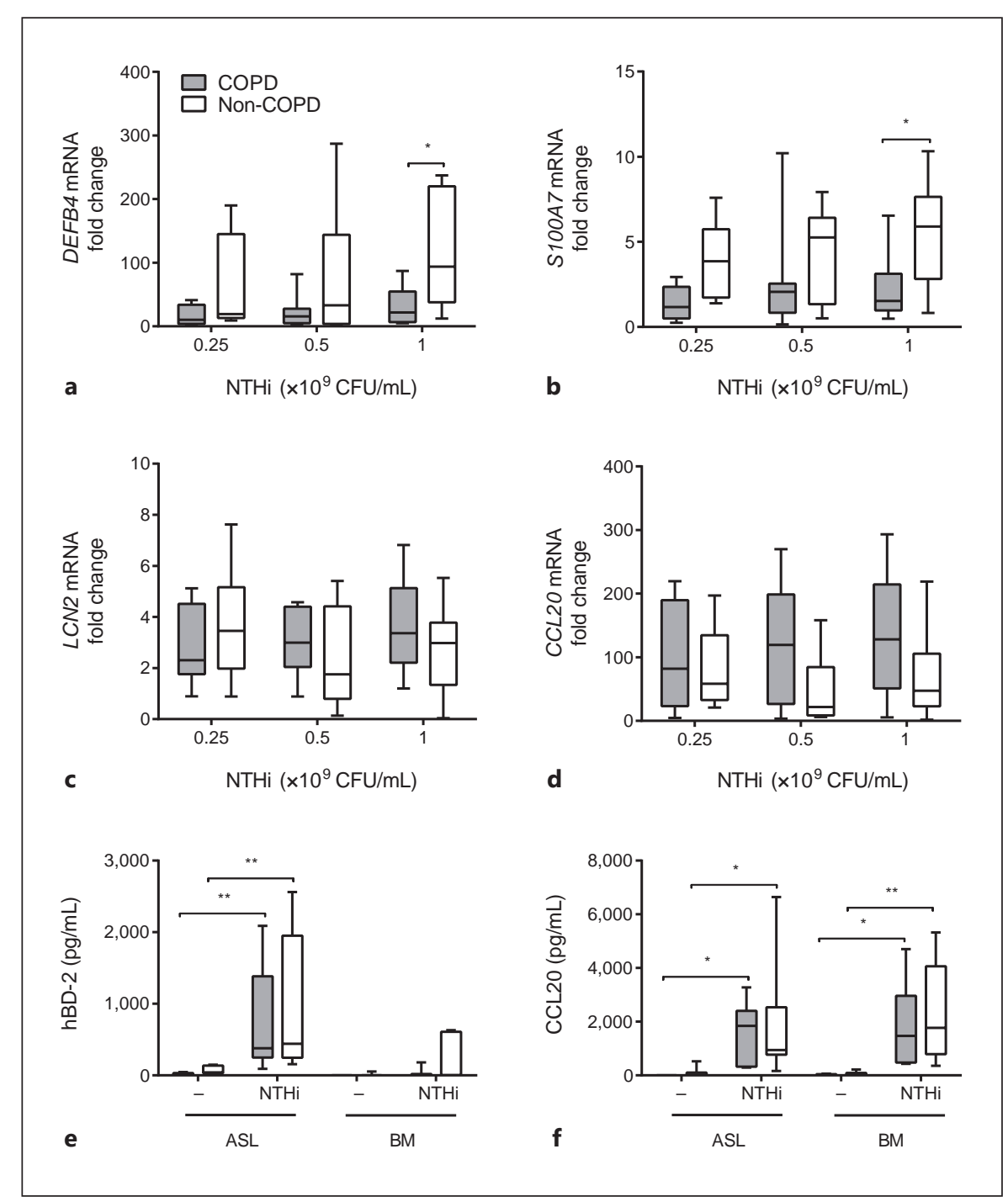

COPD and non-COPD at 3 and $12 \mathrm{~h}$ of stimulation (Fig. 3a-d). These findings suggest that the attenuated antibacterial defense of COPD airway epithelial cells observed $48 \mathrm{~h}$ after microbial stimulation was not accompanied by differences in the early effects of microbial stimuli on AMP expression, but possibly related to the lower expression of hBD-2 and S100A7 in COPD cultures only at later time points.

Cell Differentiation, Barrier Function and Expression of Regulatory Genes Do Not Differ between COPD and Non-COPD ALI-PBEC

We further studied the cause of the impaired expression of AMPs in COPD airway epithelial cells. Previous research has demonstrated a reduced host defense func- tion of airway epithelial cells from severe COPD patients due to impaired cell differentiation $[5,27]$. In addition, it was reported that COPD airway epithelial cells display a reduced barrier function [4]. Therefore, we examined cell differentiation and the epithelial barrier integrity of COPD and non-COPD ALI-PBEC. In contrast to previous findings, we did not observe differences in mRNA expression levels of the club cell marker SCGB1A1, ciliated cell marker FOXJ1, goblet cell marker MUC5AC, and basal cell marker TP63 (Fig. 4a-d). Moreover, we did not observe differences in the epithelial barrier function between COPD and non-COPD ALI-PBEC, based on TEER measurements (Fig. 4e). Furthermore, COPD ALI-PBEC did not display low TEER values as observed in a previous study [4]. These findings suggest that the altered NTHi- 
Fig. 3. Differences in early- and late-induced transcriptional responses between COPD and non-COPD ALI-PBEC. Time course of NTHi-induced mRNA expression in COPD (gray bars, $n=12$ ) and nonCOPD AL-PBEC (white bars, $n=9$ ). COPD and non-COPD ALI-PBEC were stimulated with $1 \times 10^{9} \mathrm{CFU} / \mathrm{mL} \mathrm{UV}$-inactivated NTHi for 3, 12, and $24 \mathrm{~h}$, afterwards mRNA expression of DEFB4/hBD-2 (a), S100A7 (b), LCN2 (c), and CCL20 (d) was examined by qPCR. Stimulations were performed in duplicate. Data are shown as the fold change compared to unstimulated cells. All results are depicted as the mean \pm SEM. The analysis of differences was conducted with an unpaired $t$ test. ${ }^{*} p<0.05$.

Fig. 4. Expression of epithelial differentiation markers and barrier function in COPD and non-COPD ALI-PBEC. Baseline mRNA expression of the cell differentiation markers SCGB1A1 (club cell; a), FOXJ1 (ciliated cell; b), MUC5AC (goblet cell; c), and TP63 (basal cell; d) was determined in differentiated ALI-PBEC from COPD (gray boxplots, $n=11$ patients) and non-COPD (white boxplots, $n=8$ patients) ALI-PBEC. Data are shown as normalized values. e The epithelial barrier integrity of COPD (gray boxplots, $n=9$ patients) and non-COPD (white boxplots, $n=7$ patients) ALI-PBEC was determined by measuring the TEER values. ALL results are shown as boxplots with whiskers from minimum to maximum or bars (means \pm SEM). The analysis of differences was conducted with a 2-way ANOVA and Bonferroni post hoc test.
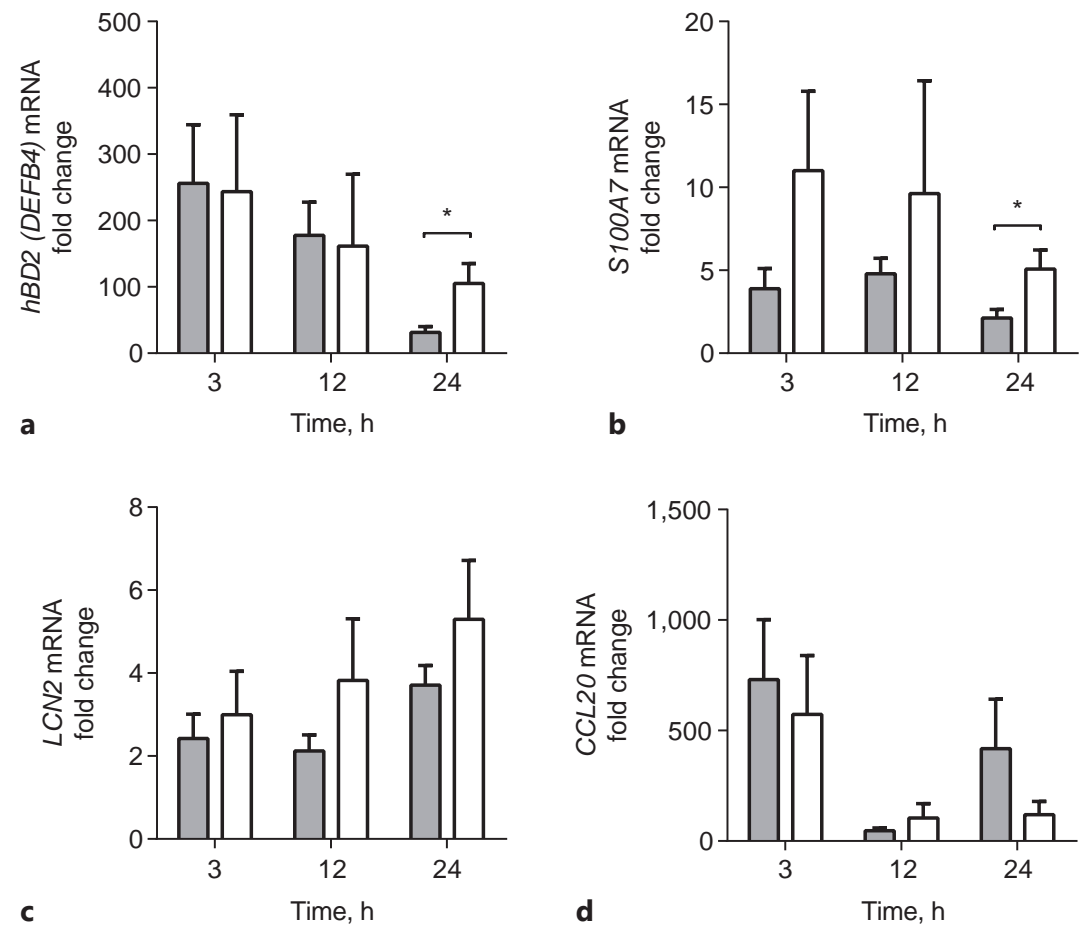
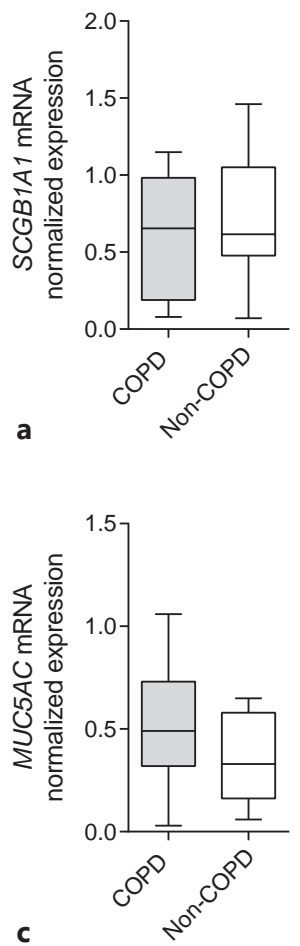
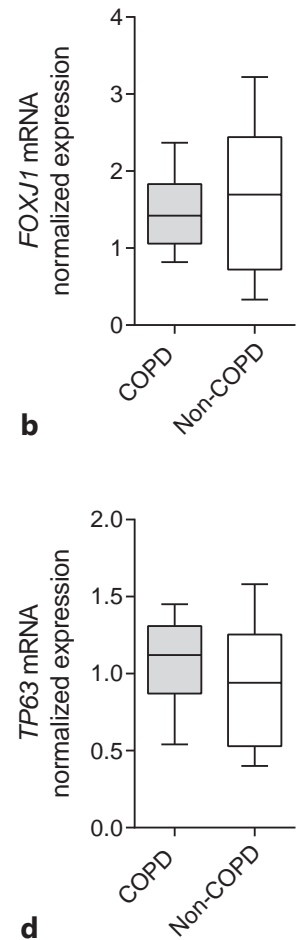

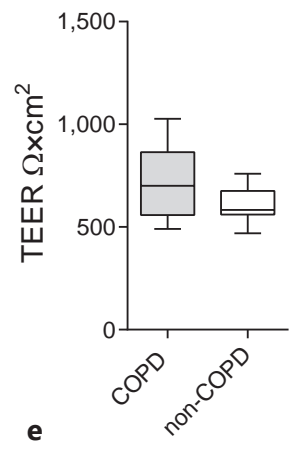

Airway Epithelial Antibacterial Defense in COPD 


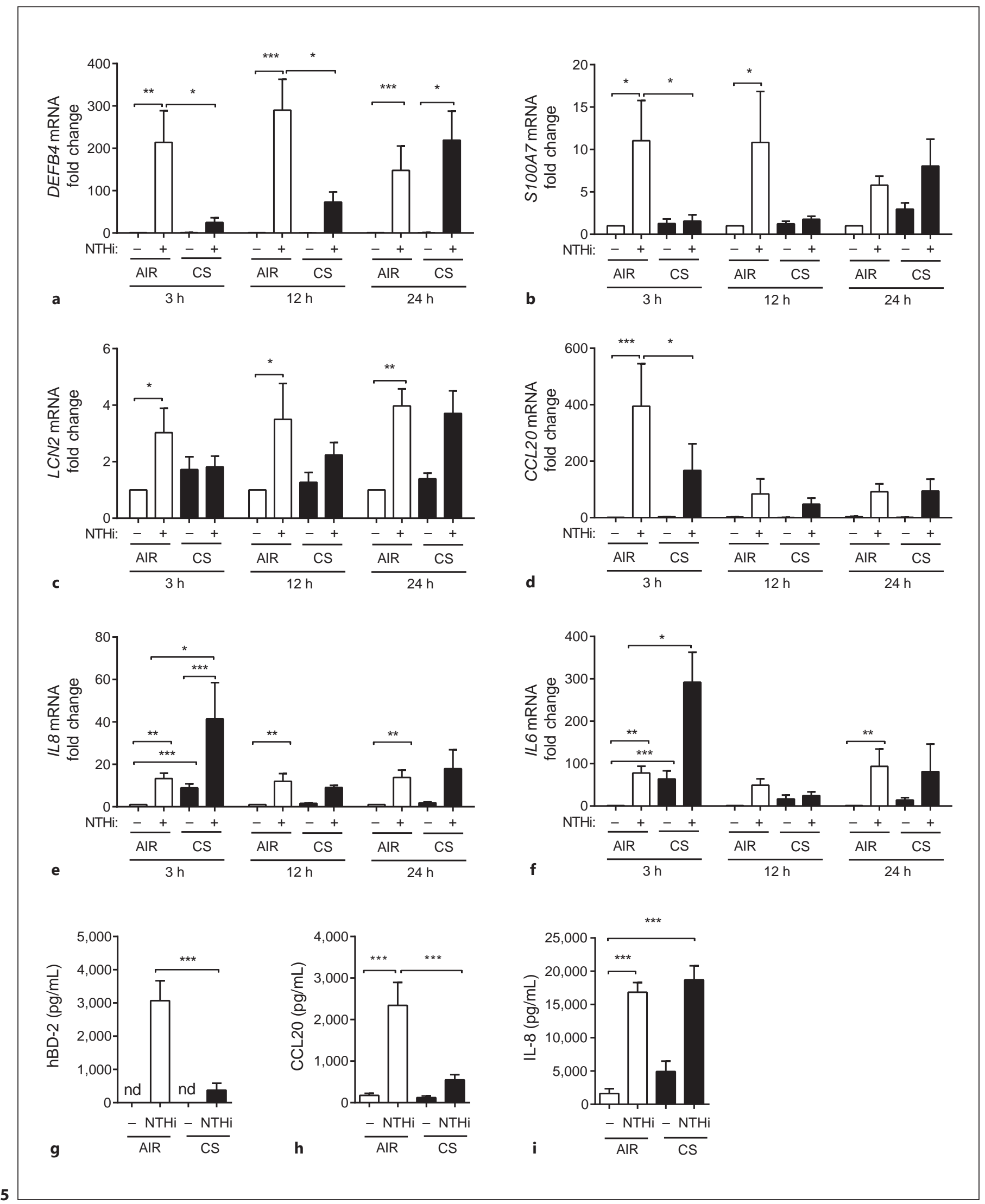

(For legend see next page.) 
induced antibacterial defense of COPD airway epithelial cells is not caused by impaired cell differentiation or a reduced barrier function. Another possible explanation for the persistence of this difference after prolonged culture could be the presence of epigenetic modifications in the epithelium from COPD patients. These modifications can lead to a variety of changes that may help to explain the observed differences. First, this differential expression might be caused by altered expression of pattern recognition receptors at later time points. It has been shown that NTHi increases the expression of TLR2 [28], and impairment of this induction in cells from COPD patients can influence late-induced innate immune responses. However, we did not observe differences in TLR2 mRNA expression between COPD and non-COPD cultures (see online suppl. Fig. S2). Second, alterations in the negativefeedback loop mechanism of the NF- $\kappa$ B signaling pathway may also result in the impaired expression of AMPs, such as differential expression of micro-RNAs, like mir-147b, the deubiquitinating enzyme/ubiquitin ligase A20, or the transcription factor ATF3 [29-31]. However, we did not observe differences in the expression of the primary mir$147 \mathrm{~b}$ transcript, and expression of $A 20$ and ATF3 mRNA (see online suppl. Fig. S2). This suggests that other mechanisms underlie the altered microbial-induced expression of AMPs in COPD airway epithelial cultures.

\section{CS Differentially Affects the Induction of AMPs and Proinflammatory Mediators in ALI-PBEC}

We next set out to investigate the effect of CS exposure on the expression of AMPs and proinflammatory mediators. This was done using a whole CS exposure model in which ALI-PBEC are exposed to mainstream smoke derived from 1 cigarette or AIR as a negative control. The exposure is for a period of $15 \mathrm{~min}$, after which the cells

Fig. 5. CS differentially modulates the innate immune gene expression. ALI-PBEC $(n=7)$ were exposed to AIR or CS and subsequently stimulated with $1 \times 10^{9} \mathrm{CFU} / \mathrm{mL}$ UV-inactivated NTHi for 3,12 , and 24 h. mRNA expression of DEFB4 (a), S100A7 (b), LCN2 (c), CCL20 (d), IL8 (e), and IL6 (f) was measured by qPCR. Stimulations were performed in duplicate. Data are shown as the fold change in mRNA compared to untreated cells. Assessment of hBD-2 (g) secretion in the apical surface liquid and CCL20 (h) and IL-8 (i) secretion in the basal medium of AIR/CS-exposed ALIPBEC $(n=7)$ stimulated with $1 \times 10^{9} \mathrm{CFU} / \mathrm{mL} \mathrm{UV}$-inactivated NTHi. Stimulations were performed in duplicate. All results are shown as the mean \pm SEM. The analysis of differences was conducted with a 1-way ANOVA and Bonferroni post hoc test (a-f), and paired $t$ test $(\mathbf{g}-\mathbf{i}) .{ }^{*} p<0.05,{ }^{* *} p<0.01,{ }^{* * *} p<0.001$.

Airway Epithelial Antibacterial Defense in COPD are stimulated with UV-inactivated NTHi for 3, 12, and $24 \mathrm{~h}$. After the indicated time points, mRNA expression was measured by qPCR. Corresponding with earlier reports [12-14], CS exposure significantly reduced the NTHi-mediated expression of DEFB4 at 3 and $12 \mathrm{~h}$ after exposure (Fig. 5a). This effect was no longer observed at $24 \mathrm{~h}$ after exposure. CS also attenuated the NTHi-induced expression of $L C N 2, S 100 A 7$, and CCL20 after $3 \mathrm{~h}$ (Fig. 5bd). In accordance with preceding studies $[14,15]$, we observed a further increase in IL-8 and IL- 6 mRNA expression upon CS and NTHi costimulation (Fig. 5e, f). We also found decreased NTHi-induced hBD-2 and CCL20 protein secretion in CS-exposed cultures (Fig. 5g, h), whereas IL-8 secretion was not attenuated and further enhanced (Fig. 6i). Overall, these data demonstrate that CS exposure differentially modulates microbial-induced innate immunity, impairing the induction of AMPs while increasing proinflammatory mediators.

\section{CS Impairs NTHi-Induced Expression of AMPs in}

Both COPD and Non-COPD ALI-PBEC

Next, we determined the effect of CS on COPD and non-COPD ALI-PBEC. As we observed an acute effect of $\mathrm{CS}$ exposure, which was primarily seen at $3 \mathrm{~h}$ after exposure, we studied the mRNA expression levels of AMPs at this particular time point. AMP expression was reduced by smoke in both COPD and non-COPD cultures, thus suggesting that the attenuation of AMP expression in our CS exposure model occurs independently of disease status (Fig. 6a-d). We did not observe a significant difference in IL- 8 mRNA expression between CS- and NTHiexposed COPD and non-COPD ALI-PBEC (Fig. 6e). This suggests that modulation of the expression of AMPs and proinflammatory mediators by CS occurs to a similar extent in COPD and non-COPD ALI-PBEC cultures.

\section{CS Inhibits NTHi-Mediated Activation of NF- $\kappa B$ but Not MAPK Signaling in ALI-PBEC}

We subsequently examined the underlying mechanism of the differential regulation of AMPs and proinflammatory mediators by CS. Microbial- and cytokinemediated expression of AMPs and proinflammatory mediators are regulated in particular by the NF- $\mathrm{BB}$ and MAPK (mitogen-activated protein kinase) signaling pathways $[16,17]$. Therefore, we examined the effect of $\mathrm{CS}$ exposure on NF- $\mathrm{KB}$ and MAPK signal transduction in ALI-PBEC. Epithelial cultures were exposed to CS or AIR as the control and subsequently stimulated with UV-inactivated NTHi at the apical surface for $30 \mathrm{~min}$. Activation of NF- $\kappa B$ was determined by assessing the phosphor-

J Innate Immun 2017;9:359-374

DOI: $10.1159 / 000455193$ 
Fig. 6. Suppression of AMPs by CS in both COPD and non-COPD ALI-PBEC. COPD (gray bars, $n=12$ patients) and non-COPD (white bars, $n=8$ patients) ALI-PBEC were exposure to AIR or CS and subsequently stimulated with $1 \times 10^{9} \mathrm{CFU} / \mathrm{mL} \mathrm{UV}$-inactivated NTHi for $3 \mathrm{~h}$. mRNA expression of DEFB4 (a), S100A7 (b), LCN2 (c), CCL20 (d), and $I L 8$ (e) was determined by qPCR. Stimulations were performed in duplicate. Data are shown as the fold change in mRNA compared to untreated cells and depicted as the mean \pm SEM. The analysis of differences was conducted with a paired $t$ test. ${ }^{*} p<0.05,{ }^{* *} p<0.01,{ }^{* * * *} p<0.0001$.

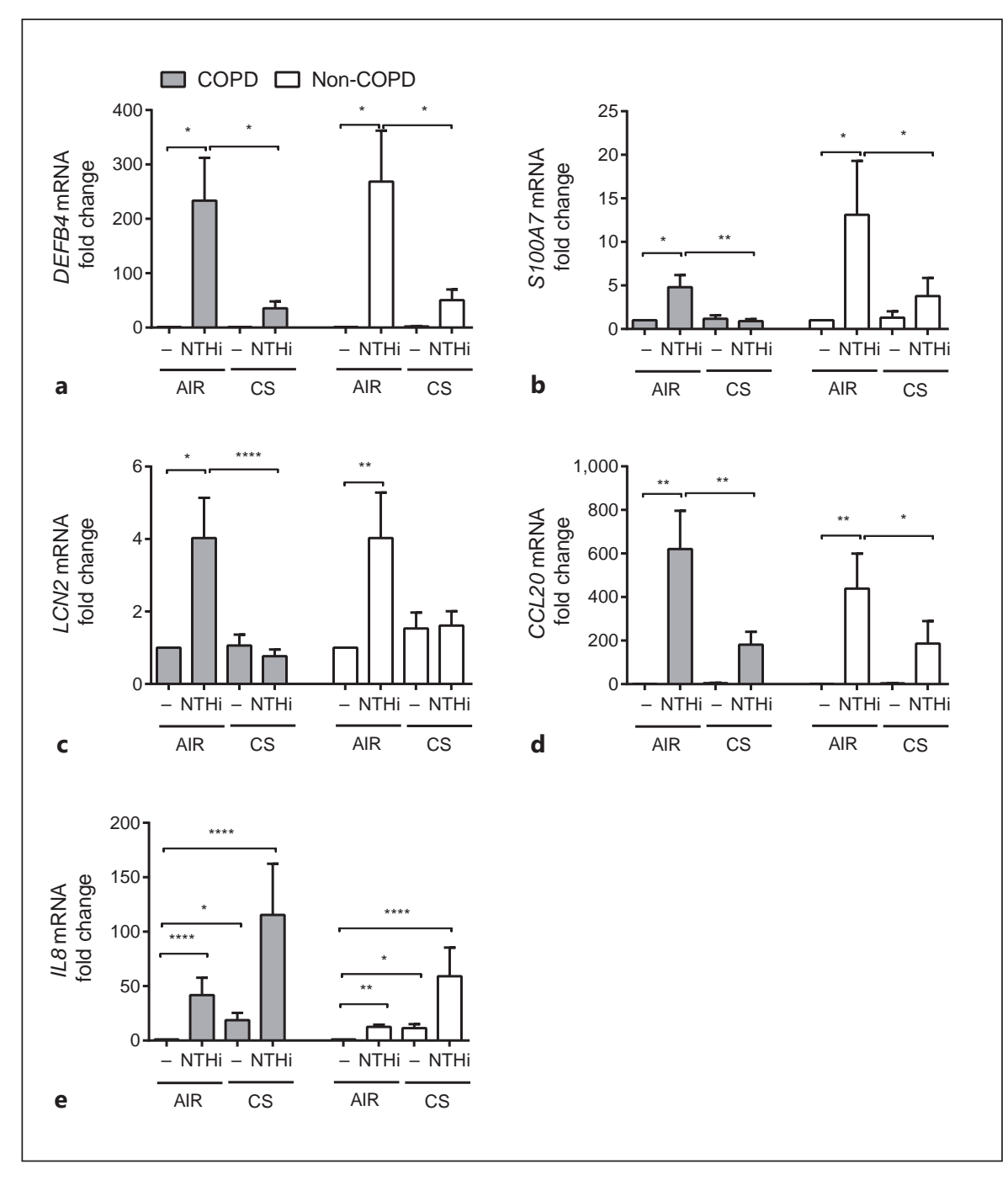

ylation of the upstream NF- $\kappa B$ signaling kinases IKK $\alpha / \beta$ and degradation of the NF- $\kappa B$ inhibitor I $\kappa B-\alpha$. MAPK signaling was evaluated by assessing the phosphorylation of p38 and ERK1/2. The NTHi stimulation of AIR-exposed cultures resulted in the enhanced activation of NF$\mathrm{\kappa B}$ signal transduction based on the phosphorylation of IKK $\alpha / \beta$ and degradation of the NFKB inhibitor I $\mathrm{K} B-\alpha$ (Fig. $7 \mathrm{a}-\mathrm{c}$ ). In contrast, CS exposure suppressed IKKa/ $\beta$ phosphorylation and IкB- $\alpha$ degradation. Both NTHiand CS-induced phosphorylation of the MAPKs ERK1/2 and p38, and CS exposure did not attenuate the NTHimediated phosphorylation of ERK1/2 and p38 (Fig. 7a, d, e). These findings demonstrate that CS alters NF- $\kappa B$ and MAPK signaling, which corresponds with the attenuated expression of AMPs and enhanced expression of proinflammatory mediators.

\section{CS Suppresses NF- $\kappa B$-Mediated Transcriptional Activity}

To further assess whether alterations in NF- $\kappa \mathrm{B}$ signaling correspond with reduced AMP expression, we investigated the nuclear translocation of NF- $\mathrm{KB}$ and transcription of early induced target genes. In agreement with impaired IKB- $\alpha$ degradation, CS inhibited nuclear translocation of the p50 and p $65 \mathrm{NF}-\kappa \mathrm{B}$ subunit, as shown by immunofluorescence staining and analysis of isolated nuclear fractions (Fig. 8a-c). To validate whether this reduced nuclear localization impaired NF-kB-mediated transcription, we examined the expression of early induced NF- $\kappa \mathrm{B}$-target genes, including the negative feedback regulators NFKBIA and ZC3H12A [32], and NFK$B I Z$, which represent an essential cotranscription factor required for AMP expression [33]. Moreover, the induc- 


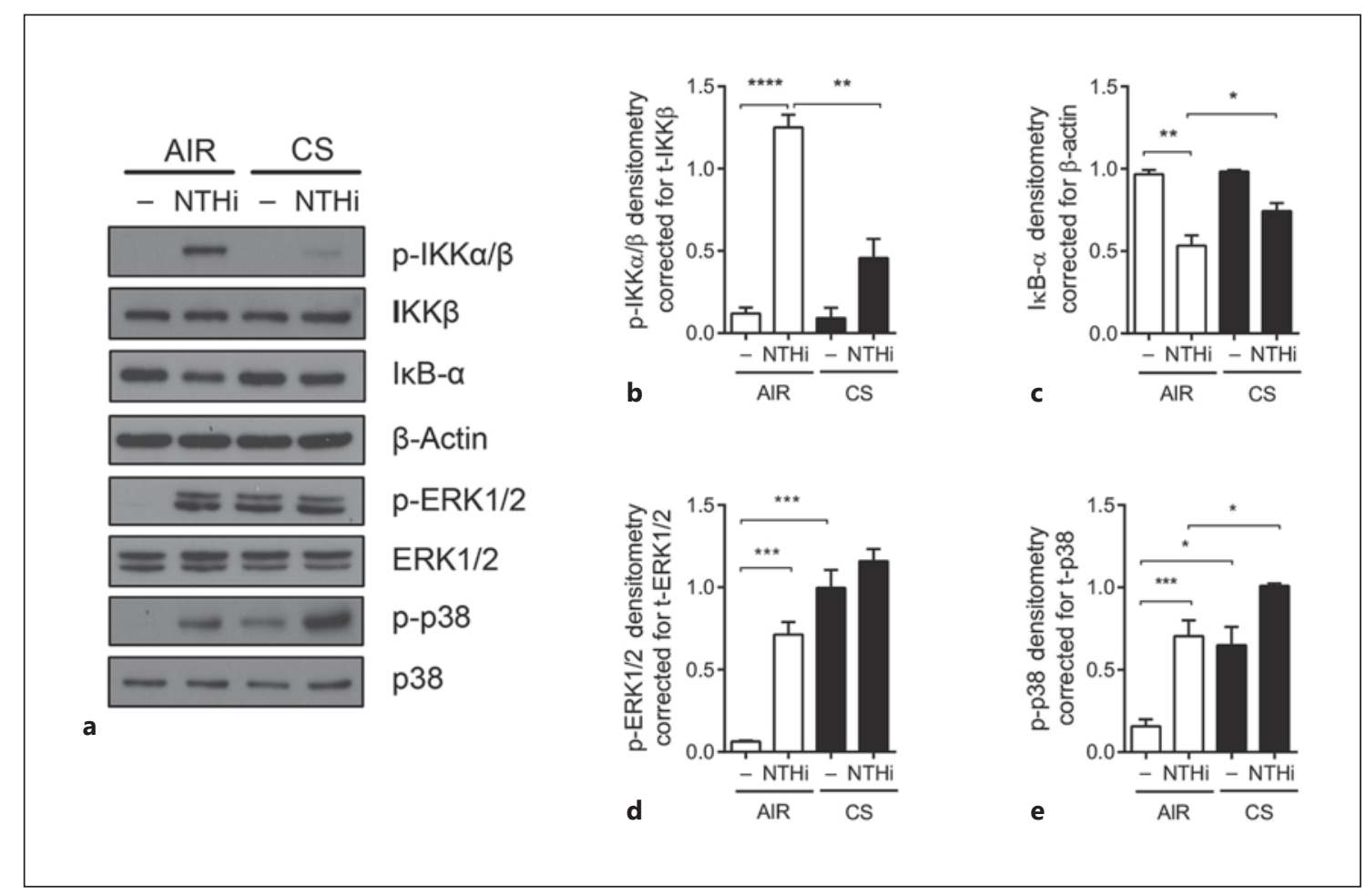

Fig. 7. CS impairs NTHi-induced NF- $\kappa B$ but not MAPK signal transduction in ALI-PBEC. a ALI-PBEC $(n=4-8)$ were exposed to AIR/CS and stimulated with $1 \times 10^{9} \mathrm{CFU} / \mathrm{mL} \mathrm{UV}$-inactivated NTHi for $30 \mathrm{~min}$. NF- $\kappa \mathrm{B}$ activation was assessed by measuring the phosphorylation of IKK $\alpha / \beta$ and degradation of I $\mathrm{B} B-\alpha$. MAPK sig-

tion of MAPK-regulated early induced target genes and AP-1 transcription factors FOS, JUN, and FOSL1 [34] was determined. CS exposure attenuated the NTHi-induced expression of NFKBIZ and NFKBIA at 60 and $120 \mathrm{~min}$ after stimulation, whereas induction of $\mathrm{ZC} 3 \mathrm{H} 12 \mathrm{~A}$ was impaired at $120 \mathrm{~min}$ (Fig. 8d). In contrast, CS exposure further increased the induction of FOS at 60 and $120 \mathrm{~min}$, and JUN and FOSL1 expression after $120 \mathrm{~min}$ of stimulation (Fig. 8e). Overall, these observations demonstrate the selective attenuation of NF- $\kappa \mathrm{B}$-mediated transcriptional activity by $\mathrm{CS}$, which reflects an impaired expression of AMPs.

\section{Discussion}

In this study we have provided evidence that the antibacterial defense of airway epithelial cells from COPD patients is decreased compared to non-COPD (ex-)smokers. In addition, we have shown that the impairment of microbial-induced expression of AMPs by CS exposure

Airway Epithelial Antibacterial Defense in COPD naling was assessed by determining the phosphorylation of ERK1/2 and p38. b-e Analysis of the data by densitometry. Results are shown as the mean \pm SEM. Analysis of differences was conducted with a paired $t$ test. ${ }^{*} p<0.05,{ }^{* *} p<0.01,{ }^{* * *} p<0.001,{ }^{* * * *} p<$ 0.0001 .

may be related to the inhibition of NF- $\mathrm{kB}$ activation. The persistence of proinflammatory responses to microbial stimulation in the presence of CS may be explained by enhanced MAPK signaling.

In contrast to the impaired antibacterial activity of cystic fibrosis airway epithelial cells at steady-state conditions $[35,36]$, COPD cultures only display an attenuated antibacterial activity upon microbial stimulation, suggesting that the induction of antibacterial factors is impaired. Indeed, a previous study reported lower hBD-2 expression in airway epithelial tissues from COPD patients compared to non-COPD (ex-)smokers [10]. In line with this study, we detected lowered NTHi-mediated expression of hBD-2/DEFB4 mRNA expression in cultured COPD airway epithelia. In addition, we also observed lower NTHi-induced S100A7 mRNA by COPD epithelial cultures. In contrast to hBD-2, S100A7 displays antibacterial activity by impairing bacterial acquisition of zinc [25], which suggests that the expression of AMPs with different modes of action is affected in COPD. In contrast to the differential regulation of DEFB4 at $24 \mathrm{~h}$ after NTHi 


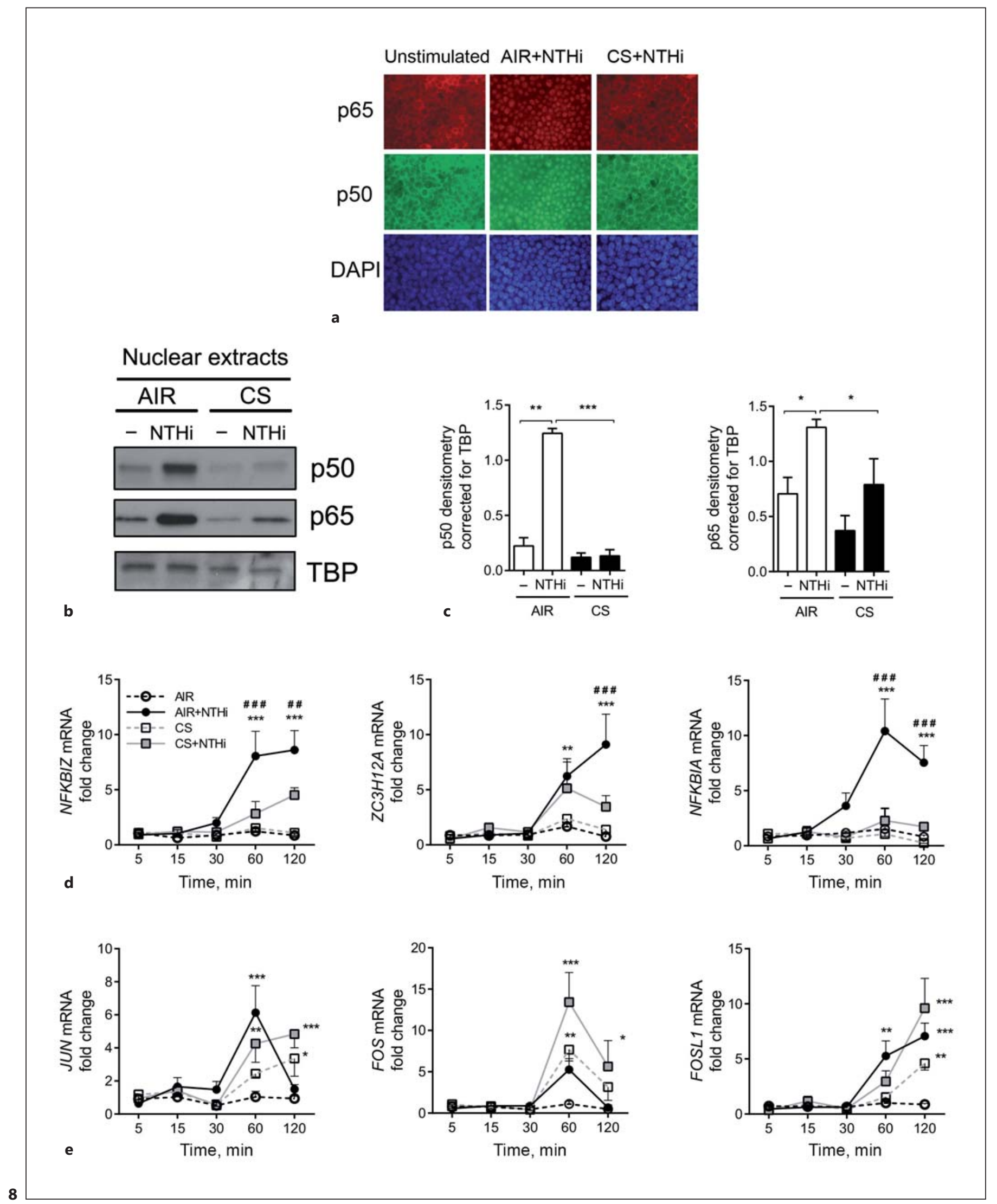

(For legend see next page.) 
stimulation, we did not observe differences in mRNA levels at earlier time points and protein secretion at $24 \mathrm{~h}$. This suggests that COPD and non-COPD airway epithelial cells differ in late-induced mRNA expression.

It has been shown that ALI-PBEC cultures from severe COPD patients display impaired epithelial differentiation and epithelial barrier integrity, which causes an impaired host defense $[4,5,27]$. However, we did not observe differences in the mRNA expression of cell differentiation markers and the epithelial barrier function. It is therefore unlikely that altered epithelial differentiation is the underlying cause for the impaired antibacterial activity of COPD cultures observed in this study. In contrast to the airway epithelial cell cultures from mild-to-moderate COPD patients used in this study, impaired epithelial differentiation in severe COPD may have an additional impact on antibacterial host defense. Impaired differentiation may, for example, lead to a loss of CFTR expression, which in turn may result in impaired activity of AMPs in the airway surface liquid [37].

We further hypothesized that the differences in lateinduced mRNA expression between COPD and nonCOPD airway epithelial cells might be caused by the differential expression of second messengers, posttranscriptional and/or posttranslational mechanisms influencing these late-induced responses. TLR2, pri-mir-147b, A20, and ATF3 are known regulators of microbial-induced innate immune responses that might be affected in COPD cultures and thereby explain the impaired antibacterial

Fig. 8. CS impairs NF- $\kappa B$ transcriptional activity by ALI-PBEC. ALI-PBEC were left untreated or exposed to AIR or CS and stimulated with UV-inactivated NTHi for $1 \mathrm{~h}$. a Cellular localization of the NF- $\kappa$ B subunits p50 and p 65 was determined by immunofluorescence microscopy. The data shown represent $n=3$ independent donors. b ALI-PBEC $(n=4)$ were exposed to AIR or CS and stimulated with $1 \times 10^{9} \mathrm{CFU} / \mathrm{mL}$ UV-inactivated NTHi for $1 \mathrm{~h}$. Protein expression of p50 and p65 was measured in isolated nuclear extracts. c The data were quantified by densitometry. ALI-PBEC were unstimulated or exposed to AIR or CS and stimulated with 1 $\times 10^{9} \mathrm{CFU} / \mathrm{ml} \mathrm{UV}$-inactivated NTHi for $1 \mathrm{~h}$. ALI-PBEC $(n=4)$ were exposed to AIR or CS and subsequently stimulated with $1 \times$ $10^{9} \mathrm{CFU} / \mathrm{mL} \mathrm{UV}$-inactivated NTHi for 5, 15, 30, 60, and $120 \mathrm{~min}$. mRNA expression of early induced NF- $\mathrm{kB}$ target genes NFKBIA, $Z C 3 H 12 A$, and NFKBIZ (d), and early induced MAPK-target genes JUN, FOS, and FOSL1 (e), was determined by qPCR. Data are shown as the fold change in mRNA compared to AIR-exposed cells. All results are shown as the mean \pm SEM. Analysis of differences was conducted with a paired $t$ test (c) and 2-way ANOVA with Bonferroni post hoc test (d, e). Significant differences compared to AIR: ${ }^{*} p<0.05,{ }^{* *} p<0.01,{ }^{* * *} p<0.001$. Significant differences compared to CS+NTHi: ${ }^{\# \#} p<0.01,{ }^{\# \#} p<0.001$.

Airway Epithelial Antibacterial Defense in COPD defense. Despite of this, we did not observe differences in the NTHi-induced mRNA expression of these regulators.

Differences in the antibacterial activity between COPD and non-COPD cell cultures were determined with an assay previously used to assess the antibacterial activity of cystic fibrosis airway epithelial cell cultures $[21,36]$. Conventional killing assays rely on the collection of apical washes or inoculation of bacteria to the apical surface that may, respectively, result in the selective collection of antimicrobial substances and dilution or modulation of the physiological conditions of the apical surface liquid. This could have a major influence on determining the antibacterial activity of epithelial cells, and the assay used in the present study is not affected by these factors.

Although it is tempting to speculate that a reduced antibacterial activity of COPD airway epithelial cells is due to a reduced expression of DEFB4 and S100A7, a clear link between these findings is missing. Indeed, other antibacterial defense mechanisms may also be affected in the epithelium of COPD patients, and contribute to the reduced antibacterial activity. In addition to various AMPs, antimicrobial lipids and reactive oxygen species also contribute to the bacterial killing activity of the airway epithelium [38, 39]. Moreover, lower antimicrobial activity might also result from other alterations in the airway surface liquid, such as a reduced $\mathrm{pH}$, and the presence of mucins, F-actin, and proteoglycans [21, 40-44]. Therefore, we cannot exclude that changes in the presence or activity of other antibacterial mediators and changes in the composition of the airway surface liquid also contributed to the reduced antibacterial activity of the COPD airway epithelial cells.

In line with previous studies demonstrating reduced antibacterial activity and inhibition of hBD-2 expression caused by CS [12-14], we showed that the expression of S100A7, LCN2, and CCL20 was also inhibited in CS-exposed COPD and non-COPD cultures. In contrast to AMPs, we showed increased NTHi-induced expression of IL-8 and IL-6 upon CS exposure. This further demonstrates that AMPs and proinflammatory mediators are differentially regulated in airway epithelial cells. The modulation of innate immune responses by CS was primarily observed $3 \mathrm{~h}$ after exposure, which is in line with the transient effect of the acute exposure [14].

Our study has several limitations. Our findings are limited to the acute effects of microbes and CS on airway epithelial innate immune responses, and chronic exposures of airway epithelial cells to both NTHi and CS may cause different effects. Moreover, differences in the smoking status of both COPD and non-COPD subjects may

J Innate Immun 2017;9:359-374 DOI: $10.1159 / 000455193$ 
have an influence on our findings. Current and ex-smokers were both included in the COPD and non-COPD group; however, we only have limited information about pack years smoked, for example. Further research regarding the influence of smoking status is therefore needed.

To assess whether alterations in AMPs and proinflammatory mediator expression are reflected by changes in cellular signal transduction pathways, we examined the effect of CS on NF- $\kappa \mathrm{B}$ and MAPK signaling. Whereas CS increased MAPK signaling, it reduced NTHi-induced NF- $\kappa B$ signal transduction. NTHi-induced activation of MAPK and NF- $\kappa B$ is mediated by the common upstream signaling kinase TAK1, which directly phosphorylates IKK $\alpha / \beta[45]$. Therefore, we speculate that CS causes selective suppression of NF- $\kappa B$ signaling by directly modulating IKK $\alpha / \beta$ phosphorylation, rather than affecting TAK1 or more upstream signaling components (see online suppl. Fig. S3). This appears in contrast to some studies that have reported increased NF- $\kappa B$ activation in COPD lung tissue [46-48]. However, this is not observed in all studies and it has been suggested that NF- $\kappa \mathrm{B}$ signaling may not contribute to COPD pathogenesis [49]. Furthermore, our results are also in line with those of a study showing that long-term passive CS exposure inhibits UVB-induced NF- $\kappa B$ signaling in the skin [50], and with earlier reports showing impaired IKKa/ $\beta$ phosphorylation and kinase activity caused by posttranslational modifications, mediated for instance by oxidative stress [51, 52]. Previous studies demonstrated the importance of NF- $\kappa B$ in both microbial-induced hBD- 2 and IL- 8 by airway epithelial cells. However, our findings suggest a more fundamental role of NF- $\kappa \mathrm{B}$ in the antibacterial defense, whereas induction of IL-8 and IL-6 persisted independent of NF- $\mathrm{BB}$. Restoration of NF- $\mathrm{KB}$ signaling may therefore improve the airway epithelial antibacterial defense in smokers. However, further research is required to study this.

As also discussed in the previous section, the role of NF- $\kappa B$ in COPD remains a matter of debate since inflammation in COPD may occur independent of NF- $\kappa B$ [49]. Based on our findings, it can be speculated that MAPK signaling has a more prominent role in CS-induced airway epithelial inflammatory responses than NF-kB. This is further supported by findings from a recent study examining ozone-induced proinflammatory responses by differentiated airway epithelial cells, revealing the MAPKdependent and NF- $\mathrm{kB}$-independent induction of inflammatory mediators [53].

Our study focused on airway epithelial responses to NTHi because of the critical role of this microbe in COPD pathogenesis [54]. However, multiple respiratory pathogens are often isolated from the airways of COPD patients and these microorganisms may affect epithelial cell function in a different way than NTHi. In recent years there has been an increased awareness of the role of the microbiome in COPD development and progression [55]. CSinduced changes in airway epithelial defense may affect the composition of this microbiome, and its altered composition may contribute to COPD development and progression. We reported in a previous study that CS exposure increased the expression of the antimicrobial protein RNase 7 in ALI-PBEC cultures [14]. This raises the possibility that, in addition to a selective downregulation of microbial-induced AMPs, the expression of other AMPs might be increased by smoke exposure. These and other changes in airway epithelial defense may contribute to changes in the microbiome. However, further research is needed to study the role of AMPs in regulating the airway microbiome in COPD.

In conclusion, our findings demonstrate that cultured airway epithelial cells from COPD patients have reduced antibacterial activity. Moreover, we observed an imbalance between the protective antibacterial defense and destructive inflammatory innate immune response of airway epithelial cells from COPD patients in response to CS. This imbalance explains in part the enhanced bacterial burden and increased lung inflammation observed in COPD development and progression. Therefore, application of exogenous AMPs to compensate for the loss of AMPs might have therapeutic potential in COPD [56]. Furthermore, the differential regulation of AMPs and proinflammatory mediators at the signal transduction level suggests that selective therapeutic targeting of airway inflammation, without affecting the beneficial antibacterial defense, might be possible.

\section{Acknowledgements}

The authors thank Annemarie van Schadewijk for her technical assistance, Winifred Broekman and Jorn Nützinger for help in collecting patient data, and the Department of Thoracic Surgery at LUMC for the collection of lung tissue. This work was supported by an unrestricted research grant from Galapagos NV, The Netherlands. H.P.H. was supported by a Program Grant (RGP001612009-C) of the Human Frontier Science Program.

\section{Disclosure Statement}

The authors have no conflicts of interest to declare.
372

J Innate Immun 2017;9:359-374

DOI: 10.1159/000455193
Amatngalim et al. 


\section{References}

1 Sethi S: Infection as a comorbidity of COPD. Eur Respir J 2010;35:1209-1215.

2 Sethi S, Mallia P, Johnston SL: New paradigms in the pathogenesis of chronic obstructive pulmonary disease II. Proc Am Thorac Soc 2009;6:532-534.

3 Arcavi L, Benowitz NL: Cigarette smoking and infection. Arch Int Med 2004;164:22062216.

4 Heijink IH, Noordhoek JA, Timens W, van Oosterhout AJM, Postma DS: Abnormalities in airway epithelial junction formation in chronic obstructive pulmonary disease. Am J Respir Crit Care Med 2014;189:14391442 .

5 Gohy ST, Detry BR, Lecocq Mn, Bouzin C, Weynand BA, Amatngalim GD, Sibille YM, Pilette C: Polymeric immunoglobulin receptor downregulation in COPD: persistence in the cultured epithelium and role of transforming growth factor- $\beta$. Am J Respir Crit Care Med 2014;190:509-521.

6 Bals R, Hiemstra PS: Innate immunity in the lung: how epithelial cells fight against respiratory pathogens. Eur Respir J 2004;23:327333.

7 Ganz T: Antimicrobial polypeptides in host defense of the respiratory tract. J Clin Invest 2002;109:693-697.

8 Evans SE, Xu Y, Tuvim MJ, Dickey BF: Inducible innate resistance of lung epithelium to infection. Annu Rev Physiol 2010;72:413-435.

9 Parameswaran GI, Sethi S, Murphy TF: Effects of bacterial infection on airway antimicrobial peptides and proteins in COPD. Chest 2011;140:611-617.

10 Pace E, Ferraro M, Minervini MI, Vitulo P, Pipitone L, Chiappara G, Siena L, Montalbano AM, Johnson M, Gjomarkaj M: Beta defensin- 2 is reduced in central but not in distal airways of smoker COPD patients. PLoS One 2012; 7:e33601.

11 Mallia P, Footitt J, Sotero R, Jepson A, Contoli M, Trujillo-Torralbo MB, Kebadze T, Aniscenko J, Oleszkiewicz G, Gray K, Message SD, Ito K, Barnes PJ, Adcock IM, Papi A, Stanciu LA, Elkin SL, Kon OM, Johnson M, Johnston SL: Rhinovirus infection induces degradation of antimicrobial peptides and secondary bacterial infection in chronic obstructive pulmonary disease. Am J Respir Crit Care Med 2012;186:1117-1124.

12 Herr C, Beisswenger C, Hess C, Kandler K, Suttorp N, Welte T, Schroeder JM, Vogelmeier C, Bals R: Suppression of pulmonary innate host defence in smokers. Thorax 2009;64: 144-149.

13 Zhang W, Case S, Bowler RP, Martin RJ, Jiang $\mathrm{D}, \mathrm{Hu} \mathrm{HW}$ : Cigarette smoke modulates $\mathrm{PGE}_{2}$ and host defence against Moraxella catarrhalis infection in human airway epithelial cells. Respirology 2011;16:508-516.

14 Amatngalim GD, van Wijck Y, de Mooij-Eijk Y, Verhoosel RM, Harder J, Lekkerkerker AN, Janssen RAJ, Hiemstra PS: Basal cells contribute to innate immunity of the airway epithelium through production of the antimicrobial protein RNase 7. J Immunol 2015;194: 3340-3350.

15 Beisswenger C, Platz J, Seifart C, Vogelmeier C, Bals R: Exposure of differentiated airway epithelial cells to volatile smoke in vitro. Respiration 2004;71:402-409.

16 Jang BC, Lim KJ, Paik JH, Kwon YK, Shin SW, Kim SC, Jung TY, Kwon TK, Cho JW, Baek WK, Kim SP, Suh MH, Suh SI: Up-regulation of human $\beta$-defensin 2 by interleukin- $1 \beta$ in A549 cells: involvement of PI3K, PKC, p38 MAPK, JNK, and NF- $\mathrm{kB}$. Biochem Biophys Res Commun 2004;320:1026-1033.

17 Bezzerri V, Borgatti M, Finotti A, Tamanini A, Gambari R, Cabrini G: Mapping the transcriptional machinery of the IL-8 gene in human bronchial epithelial cells. J Immunol 2011;187:6069-6081.

18 van Wetering S, Zuyderduyn S, Ninaber DK, van Sterkenburg MAJA, Rabe KF, Hiemstra PS: Epithelial differentiation is a determinant in the production of eotaxin- 2 and -3 by bronchial epithelial cells in response to IL-4 and IL-13. Mol Immunol 2007;44:803-811.

19 Vestbo J, Hurd SS, Agusti AG, Jones PW, Vogelmeier C, Anzueto A, Barnes PJ, Fabbri LM, Martinez FJ, Nishimura M, Stockley RA, Sin DD, Rodriguez-Roisin R: Global strategy for the diagnosis, management, and prevention of chronic obstructive pulmonary disease. Am J Respir Crit Care Med 2013;187:347365.

20 Groeneveld K, van Alphen L, Eijk PP, Visschers G, Jansen HM, Zanen HC: Endogenous and exogenous reinfections by Haemophilus influenzae in patients with chronic obstructive pulmonary disease: the effect of antibiotic treatment on persistence. J Infect Dis 1990;161:512-517.

21 Pezzulo AA, Tang XX, Hoegger MJ, Abou Alaiwa MH, Ramachandran S, Moninger TO, Karp PH, Wohlford-Lenane CL, Haagsman HP, van Eijk M, Banfi B, Horswill AR, Stoltz DA, McCray PB, Welsh MJ, Zabner J: Reduced airway surface $\mathrm{pH}$ impairs bacterial killing in the porcine cystic fibrosis lung. $\mathrm{Na}$ ture 2012;487:109-113.

22 Proud D, Sanders SP, Wiehler S: Human rhinovirus infection induces airway epithelial cell production of human $\beta$-defensin 2 both in vitro and in vivo. J Immunol 2004;172:46374645.

23 Singh PK, Jia HP, Wiles K, Hesselberth J, Liu L, Conway BA, Greenberg EP, Valore EV, Welsh MJ, Ganz T, Tack BF, McCray PB: Production of $\beta$-defensins by human airway epithelia. Proc Natl Acad Sci USA 1998;95: 14961-14966.

24 Starner TD, Barker CK, Jia HP, Kang Y, McCray PB: CCL20 is an inducible product of human airway epithelia with innate immune properties. Am J Respir Cell Mol Biol 2003;29: 627-633.
25 Glaser R, Harder J, Lange H, Bartels J, Christophers E, Schroder JM: Antimicrobial psoriasin (S100A7) protects human skin from Escherichia coli infection. Nat Immunol 2005; 6:57-64.

26 Flo TH, Smith KD, Sato S, Rodriguez DJ, Holmes MA, Strong RK, Akira S, Aderem A: Lipocalin 2 mediates an innate immune response to bacterial infection by sequestrating iron. Nature 2004;432:917-921.

27 Gohy ST, Hupin C, Fregimilicka C, Detry BR, Bouzin C, Gaide Chevronay H, Lecocq Mn, Weynand B, Ladjemi MZ, Pierreux CE, Birembaut $\mathrm{P}$, Polette $\mathrm{M}$, Pilette $\mathrm{C}$ : Imprinting of the COPD airway epithelium for dedifferentiation and mesenchymal transition. Eur Respir J 2015;45:1258-1272.

28 Mikami F, Lim JH, Ishinaga H, Ha UH, Gu H, Koga T, Jono H, Kai H, Li JD: The Transforming growth factor- $\beta$-Smad $3 / 4$ signaling pathway acts as a positive regulator for TLR2 induction by bacteria via a dual mechanism involving functional cooperation with NF- $\mathrm{KB}$ and MAPK phosphatase 1-dependent negative cross-talk with p38 MAPK. J Biol Chem 2006;281:22397-22408.

29 Liu G, Friggeri A, Yang Y, Park YJ, Tsuruta Y, Abraham E: miR-147, a microRNA that is induced upon Toll-like receptor stimulation, regulates murine macrophage inflammatory responses. Proc Natl Acad Sci USA 2009; 106 : 15819-15824.

30 Boone DL, Turer EE, Lee EG, Ahmad RC, Wheeler MT, Tsui C, Hurley P, Chien M, Chai S, Hitotsumatsu O, McNally E, Pickart $\mathrm{C}$, Ma A: The ubiquitin-modifying enzyme A20 is required for termination of Toll-like receptor responses. Nat Immunol 2004;5: 1052-1060.

31 Gilchrist M, Thorsson V, Li B, Rust AG, Korb M, Kennedy K, Hai T, Bolouri H, Aderem A: Systems biology approaches identify ATF3 as a negative regulator of Toll-like receptor 4 . Nature 2006;441:173-178.

32 Iwasaki H, Takeuchi O, Teraguchi S, Matsushita $\mathrm{K}$, Uehata T, Kuniyoshi K, Satoh T, Saitoh T, Matsushita M, Standley DM, Akira $\mathrm{S}$ : The IкB kinase complex regulates the stability of cytokine-encoding mRNA induced by TLR-IL-1R by controlling degradation of regnase-1. Nat Immunol 2011;12:11671175.

33 Kao CY, Kim C, Huang F, Wu R: Requirements for two proximal NF- $\kappa B$ binding sites and $\mathrm{I}-\mathrm{\kappa B}-\zeta$ in IL-17A-induced human $\beta$ defensin 2 expression by conducting airway epithelium. J Biol Chem 2008;283:1530915318.

34 Karin M: The regulation of AP-1 activity by mitogen-activated protein kinases. J Biol Chem 1995;270:16483-16486.

35 Smith JJ, Travis SM, Greenberg EP, Welsh MJ: Cystic fibrosis airway epithelia fail to kill bacteria because of abnormal airway surface fluid. Cell 1996;85:229-236. 
36 Shah VS, Meyerholz DK, Tang XX, Reznikov L, Abou Alaiwa M, Ernst SE, Karp PH, Wohlford-Lenane CL, Heilmann KP, Leidinger MR, Allen PD, Zabner J, McCray PB, Ostedgaard LS, Stoltz DA, Randak CO, Welsh MJ: Airway acidification initiates host defense abnormalities in cystic fibrosis mice. Science 2016;351:503-507.

37 Puchelle E, Zahm JM, Tournier JM, Coraux C: Airway epithelial repair, regeneration, and remodeling after injury in chronic obstructive pulmonary disease. Proc Am Thorac Soc 2006;3:726-733.

38 Do TQ, Moshkani S, Castillo P, Anunta S, Pogosyan A, Cheung A, Marbois B, Faull KF, Ernst W, Chiang SM, Fujii G, Clarke CF, Foster K, Porter E: Lipids including cholesteryl linoleate and cholesteryl arachidonate contribute to the inherent antibacterial activity of human nasal fluid. J Immunol 2008;181: 4177-4187.

39 Moskwa P, Lorentzen D, Excoffon KJDA, Zabner J, McCray PB, Nauseef WM, Dupuy C, Bánfi B: A novel host defense system of airways is defective in cystic fibrosis. Am J Respir Crit Care Med 2007;175:174-183.

40 Abou Alaiwa MH, Reznikov LR, Gansemer ND, Sheets KA, Horswill AR, Stoltz DA, Zabner J, Welsh MJ: $\mathrm{pH}$ modulates the activity and synergism of the airway surface liquid antimicrobials $\beta$-defensin-3 and LL-37. Proc Natl Acad Sci USA 2014;111:18703-18708.

41 Felgentreff K, Beisswenger C, Griese M, Gulder T, Bringmann G, Bals R: The antimicrobial peptide cathelicidin interacts with airway mucus. Peptides 2006;27:3100-3106.

42 Weiner DJ, Bucki R, Janmey PA: The antimicrobial activity of the cathelicidin LL37 is inhibited by F-actin bundles and restored by gelsolin. Am J Respir Cell Mol Biol 2003;28: 738-745.
43 Baranska-Rybak W, Sonesson A, Nowicki R, Schmidtchen A: Glycosaminoglycans inhibit the antibacterial activity of LL-37 in biological fluids. J Antimicrob Chemother 2006;57:260265.

44 Bergsson G, Reeves EP, McNally P, Chotirmall SH, Greene CM, Greally P, Murphy P, O’Neill SJ, McElvaney NG: LL-37 complexation with glycosaminoglycans in cystic fibrosis lungs inhibits antimicrobial activity, which can be restored by hypertonic saline. J Immunol 2009; 183:543-551.

45 Shuto T, Xu H, Wang B, Han J, Kai H, Gu XX, Murphy TF, Lim DJ, Li JD: Activation of NF$\mathrm{KB}$ by nontypeable Hemophilus influenzae is mediated by toll-like receptor 2-TAK1-dependent NIK-IKK $\alpha / \beta$-IкB $\alpha$ and MKK3/6P38MAP kinase signaling pathways in epithelial cells. Proc Natl Acad Sci USA 2001;98: 8774-8779.

46 Di Stefano A, Caramori G, Oates T, Capelli A, Lusuardi M, Gnemmi I, Ioli F, Chung KF, Donner CF, Barnes PJ, Adcock IM: Increased expression of nuclear factor- $\kappa \mathrm{B}$ in bronchial biopsies from smokers and patients with COPD. Eur Respir J 2002;20:556-563.

47 Szulakowski P, Crowther AJL, Jiménez LA, Donaldson K, Mayer R, Leonard TB, MacNee W, Drost EM: The effect of smoking on the transcriptional regulation of lung inflammation in patients with chronic obstructive pulmonary disease. Am J Respir Crit Care Med 2006;174:41-50.

48 Yagi O, Aoshiba K, Nagai A: Activation of nuclear factor- $\mathrm{\kappa B}$ in airway epithelial cells in patients with chronic obstructive pulmonary disease. Respiration 2006;73:610-616.
49 Rastrick JMD, Stevenson CS, Eltom S, Grace M, Davies M, Kilty I, Evans SM, Pasparakis M, Catley MC, Lawrence T, Adcock IM, Belvisi MG, Birrell MA: Cigarette smoke induced airway inflammation is independent of NF- $\kappa B$ signalling. PLoS One 2013;8:e54128.

50 Gottipati KR, Poulsen H, Starcher B: Passive cigarette smoke exposure inhibits ultraviolet light B-induced skin tumors in SKH-1 hairless mice by blocking the nuclear factor kappa B signalling pathway. Exp Dermatol 2008;17: 780-787.

51 Korn SH, Wouters EFM, Vos N, JanssenHeininger YMW: Cytokine-induced activation of nuclear factor- $\mathrm{kB}$ is inhibited by hydrogen peroxide through oxidative inactivation of IkB kinase. J Biol Chem 2001;276: 35693-35700.

52 Reynaert NL, Ckless K, Korn SH, Vos N, Guala AS, Wouters EFM, van der Vliet A, JanssenHeininger YMW: Nitric oxide represses inhibitory $\kappa \mathrm{B}$ kinase through S-nitrosylation. Proc Natl Acad Sci USA 2004;101:8945-8950.

53 McCullough SD, Duncan KE, Swanton SM, Dailey LA, Diaz-Sanchez D, Devlin RB: Ozone induces a proinflammatory response in primary human bronchial epithelial cells through mitogen-activated protein kinase activation without nuclear factor- $\mathrm{\kappa B}$ activation. Am J Respir Cell Mol Biol 2014;51:426-435.

54 Murphy TF, Brauer AL, Schiffmacher AT, Sethi S: Persistent colonization by Haemophilus influenzae in chronic obstructive pulmonary disease. Am J Respir Crit Care Med 2004; 170:266-272.

55 Mammen MJ, Sethi S: COPD and the microbiome. Respirology 2016;21:590-599.

56 Hiemstra PS, Amatngalim GD, van der Does AM, Taube C: Antimicrobial peptides and innate lung defenses: role in infectious and noninfectious lung diseases and therapeutic applications. Chest 2016;149:545-551. 